

Working Paper

WP 2012-262

\title{
Induced Entry into the Social Security Disability Program: Using Past SGA Changes as a Natural Experiment
}

Nicole Maestas, Kathleen J. Mullen and Gema Zamarro

\begin{tabular}{|l|l|}
\hline $\mathrm{M}$ & $\mathrm{R}$ \\
\hline $\mathrm{R}$ & $\mathrm{C}$ \\
\hline
\end{tabular}

Project \#: UM11-Q1 



\title{
Induced Entry into the Social Security Disability Program: Using Past SGA Changes as a Natural Experiment
}

\author{
Nicole Maestas, Kathleen J. Mullen and Gema Zamarro \\ RAND Corporation
}

August 2012

\author{
Michigan Retirement Research Center \\ University of Michigan \\ P.O. Box 1248 \\ Ann Arbor, MI 48104 \\ www.mrrc.isr.umich.edu
}

(734) 615-0422

\section{Acknowledgements}

This work was supported by a grant from the Social Security Administration through the Michigan Retirement Research Center (Grant \# 5 RRC08098401-03-00). The findings and conclusions expressed are solely those of the author and do not represent the views of the Social Security Administration, any agency of the Federal government, or the Michigan Retirement Research Center. 


\title{
Induced Entry into the Social Security Disability Program: Using Past SGA Changes as a Natural Experiment
}

\begin{abstract}
The number of American adults receiving benefits from the Social Security Disability Insurance (SSDI) program has increased dramatically over the past several decades. A proposed solution to rising program costs is to change program rules to encourage fully or partially recovered SSDI beneficiaries to return to work. One such option is a benefit offset policy, which would reduce SSDI benefits by $\$ 1$ for every $\$ 2$ of earned income. While a benefit offset could generate savings from increased labor supply and program exit among current beneficiaries, it could also generate unintended costs if the more generous work rules induce significant numbers of working individuals to apply for benefits. In this paper we examine how past changes in a closely related program parameter, the Substantial Gainful Activity (SGA) threshold, have affected SSDI applications. We exploit changes over time and across states in real relative SGA levels, relative to local average wages. We find that a 7 percentage point $(30 \%)$ increase in the real relative SGA (on par with the 1999 increase from $\$ 500$ to $\$ 700$ per month) was associated with a 4.7\% increase in applications.
\end{abstract}

\section{Authors’ Acknowledgements}

Corresponding author: Gema Zamarro, RAND Corporation, 1776 Main Street, Santa Monica, CA 90407-2138, Tel: 310-393-0411, Email: gzamarro@rand.org. We are especially grateful to John Travis Jones and Bob Weathers for numerous helpful conversations and assistance with the SSA administrative data. We thank Sarah Kups for excellent research assistance and seminar participants of the RAND L\&P brownbag series for helpful comments. This research was supported by a grant from the U.S. Social Security Administration through the Michigan Retirement Research Center. The opinions and conclusions expressed are solely those of the authors and do not represent the opinions or policy of SSA or any agency of the Federal Government. 


\section{Introduction}

The number of American adults receiving benefits from the Social Security Disability Insurance (SSDI) program has increased dramatically over the past several decades. Duggan, Singleton and Song (2007) estimate that SSDI enrollment increased nearly 50\% among 45 to 64 year old individuals and more than doubled among 25 to 44-year olds between 1983 and 2005. A proposed solution to rising program costs is to change program rules to encourage fully or partially recovered SSDI beneficiaries to return to work. An example of this type of policy is a benefit offset policy. Under such a policy, SSDI benefits would be reduced by $\$ 1$ for every $\$ 2$ of earnings above the Substantial Gainful Activity (SGA) threshold, rather than fully suspended, as under the current rules. Introducing a benefit offset could generate savings if current SSDI beneficiaries respond by increasing their earnings above SGA (thereby reducing benefits) or by exiting the program (e.g., if the policy encourages beneficiaries to successfully "test" their work capacity beyond the Trial Work Period). Yet it could also create unintended costs if the more generous work rules induce significant numbers of working individuals to apply for benefits.

Under the Ticket to Work Incentive and Work Incentives Improvement Act of 1999, the Social Security Administration (SSA) is required to estimate the potential effects of a benefit offset on the labor supply of current beneficiaries and on program entry. ${ }^{1}$ This paper aims to provide evidence on the behavioral response on the application margin to past program changes. Specifically, we examine how changes in a closely related program parameter, the SGA threshold, have affected SSDI applications rates. ${ }^{2}$ We exploit both declines in the real SGA

\footnotetext{
${ }^{1}$ At present, SSA has commissioned three major studies of the benefit offset, the ongoing Benefit Offset National Demonstration Project (see www.ssa.gov/disabilityresearch/offsetnational.htm) and two induced entry research design studies (Tuma, 2001; Maestas, Mullen and Zamarro, 2010).

${ }^{2}$ In a related paper, Schimmel, Stapleton and Song (2009) study the effect of the 1999 SGA change on labor supply and earnings of current SSDI beneficiaries. They find that approximately $1 \%$ of current beneficiaries increased their
} 
threshold arising from inflation as it erodes the value of the nominal SGA threshold over time as well as two large increases arising from policy changes in 1990 and 1999. In addition, we make use of variation in the relative impact of changes in the SGA threshold across states with different average wage levels.

While there exist no past policy changes that are exactly equivalent to introducing a benefit offset, changes in the SGA threshold are quite close inasmuch as they change the individual budget constraint in a similar hours/earnings region, and thus offer a potentially instructive natural experiment. Like the benefit offset, an increase in the SGA level may prompt some beneficiaries to venture into the workforce if the higher threshold makes available new options for combining work with benefit receipt; but the availability of new options may also make the SSDI program more attractive to new applicants who are currently working. In this paper we exploit changes in the SGA threshold as a way to learn about possible induced entry effects from a benefit offset. In particular, we present a reduced form estimate of induced entry arising from variation in the SGA level. Our preferred estimates imply that the 1999 increase in the nominal SGA threshold from $\$ 500$ to $\$ 700$ led to a $4.7 \%$ increase in SSDI applications, or 0.2 new SSDI applications per 1,000 individuals. As we discuss below, this estimate is likely to be a good approximation of potential induced entry from a benefit offset if the marginal applicant has low potential wages

A range of estimates of the magnitude of potential induced entry under a new benefit offset policy currently exist. McLaughlin (1994) estimates the size of the medically eligible nonbeneficiary population with earnings above the SGA using data from the 1978 Survey of Disability and Work and, assuming that $20 \%$ of this group would apply for benefits, concludes

earnings above the old SGA level, yet still below the new SGA level, and that another $1 \%$ of current beneficiaries reduced earnings that were previously above both SGA levels to under the new SGA level (that is, they were less likely to exit the program). 
that a $\$ 1$ for $\$ 2$ benefit offset would increase the SSDI rolls by roughly 400,000 beneficiaries over a 10-year period (approximately 6.4 percent). Hoynes and Moffitt (1999) provide indirect evidence on the number of potentially induced entrants; they simulate the financial impacts of a \$1 for \$2 benefit offset, on current and potential SSDI recipients and conclude that the financial incentives for entering SSDI under a benefit offset policy may be substantial: part-time (20 hours/week) workers earning the median wage could more than double their income if they entered SSDI under the new rules, and even full-time workers could increase their earnings by 35-46 percent. Most recently, Benitez-Silva, Buchinsky and Rust (2006) use data from the Health and Retirement Study to calibrate a life-cycle model of labor supply and SSDI claiming in order to estimate induced entry from a $\$ 1$ for $\$ 2$ benefit offset. They estimate that the benefit offset would increase SSDI applications by 2.2 percent and SSDI entrants by 3.2 percent. $^{3}$

\section{Institutional Background}

SSA defines disability as the inability to engage in any substantial gainful work activity (SGA) because of a medically-determinable physical or mental impairment that is expected to result in death, or that has lasted or is expected to last for a continuous period of not less than 12 months. SSA operationalizes this definition by setting a monthly earnings threshold $(\$ 1,000$ in 2011) over which individuals are disqualified from receiving SSDI benefits. Thus, the SGA threshold is a fundamental program parameter, defining both initial eligibility and ongoing entitlement to benefits (after a 9 month (non-consecutive) Trial Work Period (TWP) and 3 month

\footnotetext{
${ }^{3}$ Other studies (e.g., Black, Daniel and Sanders, 2002; Autor and Duggan, 2003) have established that SSDI application rates respond to changes in employment opportunities and benefit replacement rates.
} 
Grace Period, in which new beneficiaries can test their ability to work by posting earnings above SGA without penalty). ${ }^{4}$

Although the SGA threshold is currently indexed to a measure of average annual wages for all employees in the United States, before 2001 the SGA threshold was set nominally and only increased infrequently. Between 1980 and 2000, the SGA threshold was raised only twicefrom $\$ 300$ to $\$ 500$ in January 1990 and from $\$ 500$ to $\$ 700$ in July 1999 . Figure 1 shows the evolution of real SGA levels for the non-blind since 1975, expressed in 2009 dollars. The SGA amount is expressed in real terms; thus periods during which the SGA decreases in real terms correspond to periods where the SGA amount is flat in nominal terms.

While the SGA level is set nationally, it is relatively more generous in areas with lower costs of living and lower average wages compared to areas with higher costs of living and higher average wages. In lower-wage areas, applying for SSDI might be more attractive if individuals are still able to work in a variety of occupations while still receiving benefits. Similarly, absolute changes in the national SGA amount will induce different relative changes in different areas of the country. To illustrate this, Figure 2A shows the density function of relative changes in the SGA amount in 1999, by state, as a percentage of the state average annual wage measured in 1998. Figure 2B provides an alternative view of the distribution of relative changes in the SGA amount in 1999, showing its geographical distribution across states. In 1999, the SGA amount rose from $\$ 500$ to $\$ 700$ per month, amounting to an average relative change of 8.6 percent of average annual wages. Importantly, there is considerable variation in the relative change across states; the coefficient of variation for the distribution is 13.2 percent.

\footnotetext{
${ }^{4}$ Successful applicants also face a 5 month Waiting Period before they begin receiving benefits in which the SGA earnings restriction holds.
} 
While raising the SGA threshold is not equivalent to introducing a benefit offset (the latter eliminates the discontinuity in the beneficiary's budget constraint, or "cash cliff," at the hours level where earnings exceed the SGA and alters the implicit tax rate for earnings above the SGA), the two policies affect the budget constraint in a similar hours/earnings region. Thus past SGA changes offer a potentially instructive natural experiment for forecasting induced entry effects of the benefit offset if it were to be implemented. Figure 3 illustrates the effects of an SGA change and introduction of a benefit offset, respectively, on an individual's budget constraint (after the TWP and Grace Period have elapsed). The solid blue line represents the SSDI budget constraint under the current policy. The dotted blue line represents how the budget constraint would be affected by a change in the SGA threshold, while the dotted red line represents how the budget constraint would be affected by a benefit offset policy. Under the current policy, those earning more than the SGA threshold are ineligible to receive SSDI benefits. Participants' net income $Y$ is reduced by the full cash benefit amount $b$ if they choose to work more than $H^{*}$ hours, where $w H^{*}=S G A$, creating a discontinuous drop in net income at the SGA threshold. An increase in the SGA level to $w H^{*^{\prime \prime}}$ would lead to higher net income for those working between $H^{*}$ and $H^{*}$ ' hours, since they would now be eligible to receive benefits. Under the benefit offset, individuals could work even more than $H^{* \prime}$ and still receive benefits, although the benefits would be reduced by $\$ 1$ for each $\$ 2$ increase in earnings until hours exceed $B$ and benefits are zero.

Generally, (medically eligible) individuals maximize utility by choosing the combination of program participation and hours of work such that their indifference curves (not shown in the figure) are tangent to the budget constraint. However, some individuals who would choose to work more than $H^{*}$ hours in the absence of SSDI may prefer to reduce their hours to $H^{*}$ in order 
to qualify for SSDI benefits under the current policy. Individuals' "breakeven points" - at which they are just indifferent between program participation (with reduced work hours) and nonparticipation - depend on utility parameters that cannot be estimated without data on individuals' wages, hours and program participation decisions. ${ }^{5}$ Without these parameters, it is difficult to relate induced entry from an SGA change directly to potential induced entry from a benefit offset. However, if we make some assumptions about individuals' potential wages, then we can make some approximate comparisons.

While at first glance it appears that the benefit offset would affect a larger hours region of the budget constraint than a change in the SGA threshold, and thus encourage more program entrants, it is important to realize that the points $H^{*}, H^{* \prime}$ and $B$ depend critically on the individual's wage rate. ${ }^{6}$ For example, an individual earning approximately the minimum wage of $\$ 5$ per hour in 1999 would have to work more than 100 hours per month $\left(H^{*}\right)$ to exceed the SGA threshold value of $\$ 500$ before July 1999 , and more than 140 hours per month $\left(H^{* \prime}\right)$ to exceed the SGA threshold value of $\$ 700$ after July 1999. In contrast, a $\$ 1$ for $\$ 2$ benefit offset for earnings above the original SGA level of $\$ 500$ per month would not exhaust benefits until 500 hours $(B)$. But if we assume that there are 40 workable hours in a week, then there are no more than 160 workable hours in a month $\left(H_{\max }\right)$. Thus, for individuals with low potential wages, the benefit offset and SGA change affect approximately the same hours region of the budget constraint. Individuals with higher wage rates will have correspondingly lower values of $H^{*}, H^{* \prime}$ and $B$, and thus a larger fraction of the total hours region would be affected by a benefit offset relative to an SGA change.

\footnotetext{
${ }^{5}$ See Maestas, Mullen and Zamarro (2010) for a more detailed discussion.

${ }^{6}$ Note that under a benefit offset these new entrants would still have to be willing to reduce their work hours below $H^{*}$ temporarily during the five-month waiting period or while waiting for a decision on their application.
} 
Thus, the potential wage determines the part of the budget constraint (hours region) that is relevant to prospective applicants. If wages are low, then individuals' access to the benefit phaseout region of the benefit offset is limited by the numbers of hours available to work; in this case, SGA-induced entry provides a relatively close approximation to likely induced entry from a benefit offset. If, on the other hand, wages are high, then SGA-induced entry is likely to be smaller than induced entry from a benefit offset. Since most SSDI beneficiaries have relatively low potential wages, it is reasonable to expect that SGA-induced entry should be close to potential induced entry from a benefit offset. ${ }^{7,8} \mathrm{We}$ also decompose the SGA-induced entry effect into new applications from different parts of the earnings distribution (i.e., below the old SGA level, between the old and new SGA levels, and above the new SGA level) in an attempt to shed light on how $H^{*}$ and $H^{* \prime}$ relate to $H_{\max }$, and thus how SGA-induced entry might relate to potential induced entry from a benefit offset.

\section{Data}

We make use of administrative applications data from SSA's 831 Disability Files, which contain disability determination records for all SSDI applications from primary claimants only (excluding dependents and survivors) that pass an initial earnings screen performed at the local field office. ${ }^{9}$ The key variables included in the 831 files are filing date and state of residence,

\footnotetext{
${ }^{7}$ For example, Maestas, Mullen and Strand (2011) estimate that the average SSDI applicant in 2005-2006 earned only $\$ 22,000$ annually in 2008 dollars in the three to five years prior to filing. Assuming 40 hours per week, this corresponds to an hourly wage rate of $\$ 8.19$, deflated to 1999 dollars.

${ }^{8}$ An additional difference between the effect of an SGA increase and a benefit offset, not represented in Figure 3, is that for people with potential earnings between the old and the new SGA threshold, an increase in the SGA would delay their completion of the TWP. In contrast, the benefit offset policy would have no effect on the duration of the TWP.

${ }^{9}$ A limitation of our data set is that it does not include application attempts made by individuals who are ineligible to receive benefits because they currently earn more than the SGA threshold. This might tell us something about the size of the potential applicant pool at the margin of the SGA threshold. However, since applicants can easily reduce
} 
which we use to construct application counts by month and state. We include applications filed by previous applicants. We examine applications filed between January 1, 1988, and December $31,2000 .{ }^{10}$ To construct application rates, we obtained state and national population counts from the U.S. Census Bureau.

In addition to the applications data, we compiled time series for several variables which could influence SSDI applications, including seasonally adjusted state and national unemployment rates from the Bureau of Labor Statistics (BLS), as well as published statistics on SSDI program parameters including allowance rates (initial and overall), average benefit levels, and recovery/termination rates from the 2000 and 2010 Annual Statistical Reports of the Social Security Disability Insurance Program and a recent SSA actuarial study (Zayatz, 2011). We used the Consumer Price Index published by BLS to convert nominal SGA levels to real SGA levels and data on state-level average wages for all employees, also obtained from BLS, to construct measures of real relative SGA levels, as described below. Table 1 presents summary statistics of these data at a national level for each year 1988-2000.

Finally, in order to examine how applications relate to applicants' earnings just prior to application, we obtained counts of applications filed in December conditional on annual nominal earnings in the current year (January-December) grouped into one of four categories: (1) below $\$ 3,600$, the annualized pre-1990 SGA threshold; (2) between $\$ 3,600$ and $\$ 6,000$, the annualized 1990 SGA threshold; (3) between $\$ 6,000$ and $\$ 8,400$, the annualized 1999 SGA threshold; and (4) above $\$ 8,4000$. These counts were created using matched data from the 831 files and SSA's Detailed Earnings Record, which contains uncapped annual earnings from box 5 (Medicare

\footnotetext{
their current earnings below the threshold by reducing their hours or quitting their job, we do not believe this presents a substantial barrier for serious applicants.

${ }^{10}$ The reason we limit our analysis to applications filed before 2001 is because the SGA moved from nominal to real terms in 2001 when it was indexed to annual average wages in the U.S. This changed the fundamental nature of the SGA parameter for (potential) beneficiaries, who no longer had to worry about the real SGA deteriorating over time.
} 
wages and tips) of individuals' W-2 forms. Because the earnings data contain annual (calendar year) earnings, we focus on applications filed in December only in order to isolate earnings in the year prior to filing the SSDI application.

\section{Methods and Empirical Results}

In this section we describe the methods used and report estimates of the effect of increasing SGA levels on SSDI applications. We follow three complementary approaches. First, we study how national SSDI application counts relate to real SGA levels at a monthly frequency, after controlling for macroeconomic trends and program parameters. Second, we exploit variation across states in real relative SGA levels due to differences in local average wages; for these models we regress annual SSDI application counts at the state level, both in levels and changes, on real relative SGA levels, controlling for state and year fixed effects in order to isolate variation within states over time. Finally, we examine changes in the distribution of prior earnings among SSDI applicants before and after the 1990 and 1999 SGA changes. Specifically, we test for changes in applications among individuals divided into four earnings categoriesbelow the pre-1990 SGA level, between the pre-1990 and 1990 SGA levels, between the 1990 and 1999 SGA levels, and above the 1999 SGA level—in an attempt to discern whether the estimated SGA-induced entry effects are likely to provide a reasonable approximation to potential induced entry from a benefit offset.

\subsection{Analysis of Monthly Application Counts Using Real SGA Changes Over Time}

As a first step in analyzing how the SGA threshold relates to SSDI applications, Figure 4 plots SSDI applications between 1988 and 2003 at a monthly frequency. There is clearly a 
seasonal pattern to SSDI applications with more applications filed in the Spring and Summer and fewer in the Fall and Winter months. During this time period, applications approximately doubled, from around 60,000 per month in the late 1980 s to 125,000 per month in 2003 , but there was considerable variation over this period, with applications increasing until the mid-90s, then decreasing until about 1998 and increasing again thereafter. In this paper, we restrict our attention to applications filed before January 2001, at which point the SGA was indexed to average wages.

The two large SGA changes took place in January 1990 and July 1999. Although the 1990 change appears to be associated with an increase in applications, this also coincided with an increase in the national unemployment rate (secondary axis of Figure 4). The 1999 change occurred in a time of falling unemployment and there is no discernable change in application counts around this period.

To quantify these effects, we estimate regression models of monthly SSDI application counts on the real SGA threshold in 2009 dollars, controlling for unemployment and programlevel variables such as the overall allowance rate, the average monthly SSDI benefit and the program exit rate due to "recovery" (i.e., terminations from the program resulting from earning above SGA or failing a continuing disability review). We include month and year fixed effects in all regressions to control for seasonal variation and trends in applications over time. Table 2 presents the estimates. The first column reports the results of a regression of SSDI application counts on the real SGA threshold only, without any control variables. We find that a $\$ 1$ increase is associated with a statistically insignificant 3 additional applications per month. Thus, a $\$ 250$ change of approximately the same size (in real terms) as the 1999 SGA increase is associated with 750 additional applications, less than a $1 \%$ increase in applications. When we add the 
(annual) unemployment rate as a control the estimated effect of the real SGA level increases to just over 4 applications per $\$ 1$ increase, or an additional 1,000 applications per month associated with an increase of the same magnitude as the 1999 SGA increase- just over a 1\% increase in applications and still statistically insignificant. On the other hand, a 1 percentage point increase in the unemployment rate is associated with a statistically significant increase of approximately 4,500 SSDI applications per month. Adding (annual) program-level variables to capture other features of the SSDI program does not affect the coefficient on the real SGA threshold, although the overall allowance rate and average monthly benefit are both associated with large and statistically significant increases in SSDI applications. ${ }^{11}$

A drawback of this approach is that it uses only variation in the real SGA threshold over time stemming from depreciation due to inflation and two large increases due to policy changes. However, it is difficult to separate changes in applications due to changes in the (real) SGA level from other confounding factors such as changes in the job environment over time. In addition, although the monthly frequency brings a tight focus on changes just before and after the policy changes, it is also a fairly noisy measure of applications, making it difficult to obtain precise estimates of the effect of SGA levels on SSDI applications. In the next subsection, we pursue a different, but complementary, approach, by relating annual application rates to real relative SGA differences at the state level.

\subsection{Analysis of Annual Application Counts Using Relative SGA Changes Across States}

We estimate models of the following type to assess how changes in the SGA affect the fraction of individuals applying for SSDI benefits:

\footnotetext{
${ }^{11}$ We also estimated models with lagged program-level variables and obtained similar results.
} 


$$
S S D I_{s t}=\alpha_{t}+\mu_{s}+\text { Sunemployment }_{s t}+\beta S G A_{s t}+\varepsilon_{s t} \text {, }
$$

where $S S D I_{s t}$ is the rate of SSDI applications per 1,000 individuals in state $s$ at time $t$. The term $\alpha_{t}$ is a year fixed effect capturing common factors such as macroeconomic conditions that influence SSDI applications in each year. In the same way, $\mu_{s}$ is a state fixed effect and controls for state-specific components of application flows that are constant over time. The regression specification also includes state- and year-specific unemployment rates. The key explanatory variable is $S G A_{s t}$ which represents the real relative SGA level in state $s$ at time $t$. The real relative SGA measure is constructed by dividing the annualized real SGA level by a moving average of three years of real annual wages in each state. We exclude the year 1999 because the SGA did not change until midway through that year. By considering real relative SGA levels we exploit two sources of variation in the SGA threshold — variation over time as well as variation across states due to differences in average wages. Importantly, the period 1988-2000 contains periods of both real (and nominal) increases and real decreases in the SGA threshold.

As a first illustration, Figures 5A and 5B show how applications in 1998, before the 1999 SGA increase, and in 2000, after the 1999 increase, relate to real relative SGA levels. As we can see in these figures, there is a positive correlation among applications and real relative SGA levels that becomes more accentuated after the 1999 SGA increase. Figures 6A and 6B show how changes in applications relate to changes in the real relative SGA levels between 1996 and 1998, when the real SGA fell while the nominal SGA remained constant, and between 1998 and 2000 , when the SGA increased in both nominal and real terms. Although it is difficult to see a relationship between changes in applications and changes in the real relative SGA in years when the real SGA declined, a striking positive relationship emerges for the years surrounding the 
1999 SGA increase. In other words, the states that experienced large increases in the real relative SGA level are the same states that experienced large increases in SSDI applications.

While suggestive, these correlations may be contaminated by differential trends over time, across states, or by macroeconomic conditions affecting the number of applications such as the unemployment rate. To control for these, we estimate equation (1) above, for all SSDI applications and separately for SSI-concurrent and SSDI only cases, respectively. Table 3 presents the results. The regression estimates imply that a one percentage point increase in the real relative SGA is associated with 0.11 new SSDI applications per 1,000 individuals and that these are almost equally divided between concurrent and SSDI only applications. This implies that an increase on par with the 1999 SGA change, which increased real relative SGA levels by 7 percentage points on average, may have increased SSDI applications by as much as $19 \% .{ }^{12}$ We also estimated regressions using a narrow range of years surrounding the 1990 and 1999 SGA increases, respectively, to try to isolate periods where the real relative SGA level increased. Specifically, we estimate regressions restricted to the years 1988-1991 and 1998-2000 (omitting 1999 as before), presented in the last two columns of Table 3. The estimates of these regressions suggest that the 1999 SGA increase was associated with a much larger increase in SSDI applications than the 1990 increase. $^{13}$

A potential problem with the regressions above is that they do not control for statespecific trends in SSDI applications that may be correlated with changes in real relative SGA levels which are driven largely by changes in average wages over time. For this reason, we estimate the same regressions in first differences. That is, we relate the change in SSDI

\footnotetext{
${ }^{12}$ We arrive at $19 \%$ by multiplying the regression coefficient 0.111 by the real relative SGA increase of 7 percentage points and dividing by the average rate of SSDI applications per 1,000 individuals (4)

${ }^{13} \mathrm{We}$ also estimated regressions of the log of the number of applications instead of the rate of applications per 1,000 individuals. The results were very similar and are available from the authors upon request.
} 
applications from year $t-1$ to year $t\left(\Delta S S D I_{s t}\right)$ to the change in the real relative SGA level in state $s\left(\Delta S G A_{s t}\right)$, controlling for state-specific trends in SSDI applications using state fixed effects. To construct the change in SSDI applications between 1998 and 1999, we annualize the total number of SSDI applications filed in January-June 1999; similarly, to construct the change in SSDI applications between 1999 and 2000, we annualize the total number of SSDI applications filed in July-December 1999. ${ }^{14}$

Estimates of this model are presented in Table 4. The estimated coefficients on the real relative SGA in levels are much smaller once we control for state-specific trends in SSDI applications and they imply that the 1999 SGA increase led to an approximately $4.7 \%$ increase in SSDI applications (significant at the $10 \%$ level). ${ }^{15}$ Whereas the model in levels attributed the increase in applications equally to changes in concurrent and SSDI only cases, the model in changes attributes the increase in total SSDI applications almost entirely to changes in applications among non-concurrent SSDI only cases. Estimates of the first-difference specification restricted to years focused around the 1990 and 1999 SGA increases, respectively, are small and imprecisely estimated.

\subsection{Analysis of Prior Earnings Relative to SGA Levels, Before and After 1990 and 1999}

Finally, we attempt to decompose the SGA-induced entry effect into new SSDI applications from applicants with earnings in the prior year that fell below the old SGA level, between the old and new SGA levels, and above the new SGA level. Specifically, we examine

\footnotetext{
${ }^{14}$ We also estimated models excluding 1999 and found similar results.

${ }^{15}$ We arrive at $4.7 \%$ by multiplying the regression coefficient 0.027 by the average real relative SGA increase of 7 percentage points in 1999, and dividing by the average number of applications per 1,000 individuals (4).
} 
changes over time in SSDI applications filed in December conditional on (nominal) earnings in the year prior to filing falling into one of four categories: (1) below the pre-1990 annualized SGA threshold; (2) between the pre-1990 and 1990 annualized SGA thresholds; (3) between the 1990 and 1999 annualized SGA thresholds; and (4) above the 1999 annualized SGA threshold. We use prior year earnings as a proxy for earnings in the absence of SSDI (see Figure 3).

Economic theory predicts that applicants whose earnings in the absence of SSDI fall below the old SGA threshold would have no reason to alter their behavior under an increased SGA threshold and thus would apply in the same numbers. Thus, SGA-induced applications should be concentrated entirely among applications with prior/counterfactual earnings above the old SGA threshold. The extent to which applications are concentrated between the old and new SGA thresholds may provide a clue as to the relative size of the benefit offset effect compared with the SGA-induced entry effect by revealing how much of the benefit phase-out region is populated by individuals on the margin of application for SSDI benefits. If SGA-induced entrants are concentrated between the old and new SGA levels, then it is reasonable to expect that the SGA-induced entry effect is a relatively good approximation to potential induced entry from a benefit offset. In 1990 and 1999, the changes in real SGA were similar in both levels and changes (see Table 1) so we expect the two natural experiments to tell the same story in terms of where the new SSDI applications were concentrated in the earnings distribution relative to the old and new SGA levels.

Figure 7 displays the application counts for each of the four earnings categories between 1988 and 2000. Recall that the national unemployment rate increased sharply just after the 1990 SGA increase, whereas the unemployment rate was falling smoothly around the time of the 1999 SGA increase (see Figure 4). This is reflected in the fact that applications increased across the 
board for each earnings category in 1990, while applications fell among all but the highest earning groups in 1999.

Since the SGA policy changes were implemented nationally, there is no control group. However, we can estimate changes in applications for the highest three earnings groups relative to the lowest earnings group, which we hypothesize should have been unaffected by the SGA policy changes. If this is true, then any changes relative to the lowest earnings group before and after the policy change, net of relative changes in non-policy years, can be attributed to the SGA policy change. To formalize this, we estimate the following regression:

$$
\Delta S S D I_{g t}=\alpha_{g}+\beta_{g} I(t=1990)+\gamma_{g} I(t=1999)+\delta \Delta \text { unemployment }_{t}+\varepsilon_{g t},
$$

where $g$ indexes earnings group (where the lowest earnings group is omitted) and $t$ indexes year, from 1989 to $2000 .^{16}$

Table 5 presents the results of this regression. The first column displays the estimated coefficients, while the second column displays the total estimated change in applications for each earnings group in 1990 and 1999, respectively, using the "difference-in-difference" estimate of the change in applications relative to the lowest earnings group in 1990/1999 vs. non-policy change years (i.e., by adding the 1990/1999 dummy to the interacted earnings group dummy). We have highlighted the estimated effects for the earnings group between the old and new SGA levels for 1990 and 1999, respectively. While we estimate that most of the new applications in 1990 are drawn from the upper part of the earnings distribution, far from the old and new SGA levels, the 1999 estimates tell the opposite story—new applications are drawn from the lower part of the earnings distribution. However, none of the estimated earnings effects are significant,

\footnotetext{
${ }^{16}$ We also estimated a model where we pooled the 1990 and 1999 changes. Specifically, we focused on changes for three years surrounding the 1990 and 1999 policy changes aggregating into three groups (below the old SGA level, between the old and new SGA levels and above the new SGA levels) where the SGA levels were taken from the appropriate year. The results were qualitatively the same.
} 
and indeed many of the hypothesized effects are estimated to have the wrong sign. Without higher frequency data on earnings, it is difficult to conclude anything meaningful about the relative size of potential induced entry from a benefit offset from these analyses.

\section{Conclusion}

Recent alarming growth in SSDI program participation has prompted policy makers to propose changing the program's work disincentives to encourage beneficiaries to re-enter the labor market and become less dependent on SSDI benefits. However, a potential unintended consequence of such a policy change may be to encourage non-beneficiaries to newly enroll in the program. In this paper, we examine how SSDI application rates have responded to past policy changes in order to gauge potential induced entry effects if SSA were to implement a proposed $\$ 1$ for $\$ 2$ benefit offset. In particular, we estimate the effect of changes in a related program parameter - the earnings threshold for Substantial Gainful Activity (SGA), above which applicants and beneficiaries are disqualified from program participation.

We take several approaches to estimating SGA-induced entry effects. First, we analyze monthly application counts at a national level controlling for macroeconomic trends and program-level variables such as allowance rate, benefit generosity and exit rate due to recovery as defined by SSA. The findings are consistent with a small positive effect, but the monthly frequency is too noisy to be able to draw meaningful conclusions. The next set of analyses use an annual frequency and exploit variation in real relative SGA levels at the state level driven by state-by-state differences in annual average wages. Our preferred regression specification of the effect of real relative SGA on SSDI application rates in first differences controls for statespecific trends in SSDI application rates. We find that a 7 percentage point increase in the real 
relative SGA - the same magnitude of the 1999 increase in nominal SGA threshold from $\$ 500$ to $\$ 700$ per month - is associated with a $4.7 \%$ increase in SSDI applications. This estimate is likely to be a good approximation of potential induced entry from a benefit offset to the degree that the marginal applicant has low potential wages, and is roughly in line with previous estimates of induced entry from a benefit offset 


\section{References}

Autor D. and M. Duggan, M. (2003) "The rise in the disability rolls and the decline in unemployment”, Quarterly Journal of Economics February 2003: 157-205.

Benitez-Silva, Hugo, Moshe Buchinsky, and John Rust. 2006. Induced Entry Effects of a $\$ 1$ for \$2 Offset in SSDI Benefits. Manuscript, State University of New York-Stony Brook.

Black, Dan, Kermit Daniel, and Seth Sanders. 2002. The Impact of Economic Conditions on Participation in Disability Programs: Evidence from the Coal Bust and Boom. The American Economic Review 92(1): 27-50.

Duggan M., Singleton, P. and J. Song (2007) "Aching to Retire? The rise in the full retirement age and its impact on the social security disability rolls", Journal of Public Economics 91: $1327-1350$.

Hoynes, Hilary W., and Robert Moffitt. 1999. Tax Rates and Work Incentives in the Social Security Disability Insurance Program: Current Law and Alternative Reforms. National Tax Journal 52(4): 623-654.

Maestas, Nicole, Kathleen Mullen and Alexander Strand, 2011. "Does Disability Insurance Receipt Discourage Work? Using Examiner Assignment to Estimate Causal Effects of SSDI Receipt.” MRRC Working Paper 2010-241.

Maestas, Nicole, Kathleen Mullen, and Gema Zamarro. 2010. "Research Designs for Estimating Induced Entry into the SSDI Program Resulting from a Benefit Offset." Santa Monica, CA: RAND Labor and Population Technical Report, TR-908-SSA.

McLaughlin, James R. 1994. Estimated Increase in OASDI Benefit Payments That Would Result from Two "Earnings Test" Type Alternatives to the Current Criteria for Cessation of Disability Benefits-Information. SSA Memorandum.

Schimmel, Jody, David C. Stapleton and Jae Song, 2009. 'How Common is `Parking’ Among Social Security Disability Insurance (SSDI) Beneficiaries? Evidence from the 1999 Change in the Level of Substantial Gainful Activity (SGA).” MRRC Working Paper 2009-220.

Tuma, Nancy. 2001. Approaches to Evaluating Induced Entry into a New SSDI Program with a \$1 Reduction in Benefits for Each \$2 in Earnings. Manuscript, Stanford University.

Zayatz, Tim (2011). "Social Security Disability Insurance Program Worker Experience," Actuarial Study No. 122, Office of the Chief Actuary, Social Security Administration. 


\begin{tabular}{|c|c|c|c|c|c|c|c|c|c|c|c|}
\hline \multirow[b]{2}{*}{ Year } & \multirow[b]{2}{*}{$\begin{array}{c}\text { Real SGA } \\
(2009 \$)\end{array}$} & \multirow{2}{*}{$\begin{array}{c}\text { Real } \\
\text { Relative } \\
\text { SGA (\%) }\end{array}$} & \multicolumn{3}{|c|}{ SSDI Applications } & \multirow{2}{*}{$\begin{array}{l}\text { SSDI Appl. } \\
\text { Rate (per } \\
\text { 1,000 Pop. } \\
\text { Ages 18- }\end{array}$} & \multirow{2}{*}{$\begin{array}{c}\text { Average } \\
\text { Unemploy. } \\
\text { Rate } \\
\end{array}$} & \multicolumn{2}{|c|}{ Allowance rate } & \multirow{2}{*}{$\begin{array}{c}\text { Real Avg. } \\
\text { Monthly } \\
\text { Benefit }\end{array}$} & \multirow{2}{*}{$\begin{array}{c}\text { Recovery } \\
\text { Rate (per } \\
\text { 1,000 } \\
\text { Ben.) }\end{array}$} \\
\hline & & & SSDI Only & $\begin{array}{c}\text { Concurrent } \\
\text { with SSI }\end{array}$ & Total & & & Initial & Overall & & \\
\hline 1988 & 544.05 & 17.87 & 412,133 & 384,687 & 796,820 & $\mathrm{~N} / \mathrm{A}$ & 5.5 & $\mathrm{~N} / \mathrm{A}$ & 40.2 & 960.25 & 13.0 \\
\hline 1989 & 519.04 & 17.32 & 439,555 & 399,433 & 838,988 & $\mathrm{~N} / \mathrm{A}$ & 5.3 & N/A & 43.2 & 961.95 & 10.5 \\
\hline 1990 & 820.72 & 27.62 & 467,672 & 457,846 & 925,518 & 6.0 & 5.6 & 39 & 43.8 & 963.85 & 9.9 \\
\hline 1991 & 787.58 & 26.54 & 517,051 & 556,999 & $1,074,050$ & 6.9 & 6.9 & 42 & 44.4 & 959.90 & 8.3 \\
\hline 1992 & 764.57 & 25.26 & 547,742 & 610,601 & $1,158,343$ & 7.4 & 7.5 & 43 & 47.7 & 957.39 & 8.6 \\
\hline 1993 & 742.34 & 24.76 & 548,554 & 659,037 & $1,207,591$ & 7.6 & 6.9 & 39 & 44.6 & 952.72 & 7.9 \\
\hline 1994 & 723.81 & 24.15 & 572,464 & 649,837 & $1,222,301$ & 7.7 & 6.1 & 34 & 43.8 & 957.46 & 9.0 \\
\hline 1995 & 703.86 & 23.39 & 548,504 & 597,547 & $1,146,051$ & 7.1 & 5.6 & 31 & 48.3 & 959.50 & 11.1 \\
\hline 1996 & 683.67 & 22.56 & 574,887 & 586,009 & $1,160,896$ & 7.2 & 5.4 & 31 & 48.8 & 962.47 & 11.3 \\
\hline 1997 & 668.34 & 21.58 & 530,646 & 498,122 & $1,028,768$ & 6.3 & 4.9 & 32 & 49.8 & 964.55 & 22.7 \\
\hline 1998 & 658.09 & 20.61 & 532,112 & 484,366 & $1,016,478$ & 6.1 & 4.5 & 35 & 52.0 & 964.89 & 10.7 \\
\hline 1999 & $901.42^{*}$ & 27.80 & 554,936 & 481,531 & $1,036,467$ & 6.2 & 4.2 & 37 & 51.7 & 971.09 & 11.6 \\
\hline 2000 & 872.10 & 26.54 & 595,608 & 511,871 & $1,107,479$ & 6.5 & 4.0 & 38 & 46.7 & 979.74 & 13.4 \\
\hline
\end{tabular}

Sources: Tabulations from 831 File (SSDI applications), Census population estimates (denominator for application rate), Bureau of Labor

${ }^{*}$ As of July (real SGA for January-June 1999 is $\$ 643.87$ ). 


\begin{tabular}{|c|c|c|c|}
\hline & (1) & (2) & (3) \\
\hline Real SGA (2009\$) & $\begin{array}{l}2.948 \\
(10.8)\end{array}$ & $\begin{array}{l}4.191 \\
(10.7)\end{array}$ & $\begin{array}{l}4.182 \\
(10.7)\end{array}$ \\
\hline Unemployment Rate & & $\begin{array}{c}4520 * * \\
(1862.0)\end{array}$ & $\begin{array}{c}4520 * * \\
(1862.0)\end{array}$ \\
\hline Overall Allowance Rate & & & $\begin{array}{c}1497 * * * \\
(189.0)\end{array}$ \\
\hline Real Avg. Monthly Benefit & & & $\begin{array}{c}1107^{* * *} \\
(215.0)\end{array}$ \\
\hline Recovery Rate & & & $\begin{array}{c}221.7 \\
(156.0)\end{array}$ \\
\hline Constant & $\begin{array}{c}78177^{* * *} \\
(9732.0)\end{array}$ & $\begin{array}{l}73137 * * * \\
(12274.0)\end{array}$ & $\begin{array}{c}-1091485^{* * *} \\
(211245.0)\end{array}$ \\
\hline $\begin{array}{l}\text { Observations } \\
\text { R-squared }\end{array}$ & $\begin{array}{l}156 \\
0.89\end{array}$ & $\begin{array}{l}156 \\
0.90\end{array}$ & $\begin{array}{l}156 \\
0.90\end{array}$ \\
\hline $\begin{array}{l}\text { Standard errors in parenthe } \\
* * * p<0.01, * * p<0.05, * p< \\
\text { Note: All specifications inclu }\end{array}$ & nonth an & year fixed & ects. \\
\hline
\end{tabular}


Table 3. Regression Results of the Effect of Relative Real SGA on Annual Applications per 1000 Inhabitants (Levels)

\begin{tabular}{|c|c|c|c|c|c|}
\hline & $\begin{array}{c}\text { Total } \\
\text { Applications }\end{array}$ & $\begin{array}{l}\text { Concurrent } \\
\text { Applications }\end{array}$ & $\begin{array}{c}\text { SSDI only } \\
\text { Applications }\end{array}$ & $\begin{array}{c}\text { Total } \\
\text { Applications } \\
\text { (1990 SGA } \\
\text { change) }\end{array}$ & $\begin{array}{c}\text { Total } \\
\text { Applications } \\
\text { (1999 SGA } \\
\text { change) }\end{array}$ \\
\hline \multirow[t]{2}{*}{$\begin{array}{l}\text { Relative Real SGA } \\
\text { (MA) }\end{array}$} & $0.111^{\star \star \star}$ & 0.060 ** & $0.051^{\star *}$ & $0.054^{*}$ & $0.208^{\star * *}$ \\
\hline & $(0.039)$ & $(0.024)$ & $(0.022)$ & $(0.028)$ & $(0.086)$ \\
\hline \multirow[t]{2}{*}{$\begin{array}{l}\text { Unemployment } \\
\text { Rate }\end{array}$} & $0.002^{\star \star \star}$ & $0.001^{\star \star \star}$ & $0.001^{\star \star \star}$ & $0.002^{\star \star \star}$ & $0.004^{*}$ \\
\hline & $(0.0004)$ & $(0.0002)$ & $(0.0002)$ & (0.0003) & $(0.002)$ \\
\hline \multirow[t]{2}{*}{ Constant } & $1.638^{\star \star}$ & $1.061^{\star \star}$ & 0.577 & $2.087^{\star \star \star}$ & -1.803 \\
\hline & $(0.769)$ & $(0.450)$ & $(0.431)$ & $(0.564)$ & (3.001) \\
\hline Year Fixed Effects & Yes & Yes & Yes & Yes & Yes \\
\hline State Fixed Effects & Yes & Yes & Yes & Yes & Yes \\
\hline Observations & 561 & 561 & 561 & 153 & 102 \\
\hline
\end{tabular}

note: ${ }^{\star \star \star} p<0.01,{ }^{\star \star} p<0.05,{ }^{\star} p<0.1$; Cluster standard errors by state presented in parenthesis 
Table 4. Regression Results of the Effect of Relative Real SGA on Annual Applications per 1000 Inhabitants (Changes)

\begin{tabular}{|l|c|c|c|c|c|}
\hline & $\begin{array}{c}\text { Change in } \\
\text { Total } \\
\text { Applications }\end{array}$ & $\begin{array}{c}\text { Change in } \\
\text { Concurrent } \\
\text { Applications }\end{array}$ & $\begin{array}{c}\text { Change in } \\
\text { SSDI only } \\
\text { Applications }\end{array}$ & $\begin{array}{c}\text { Change in } \\
\text { Total } \\
\text { Applications } \\
\text { (1990 SGA } \\
\text { change) }\end{array}$ & $\begin{array}{c}\text { Change in } \\
\text { Total } \\
\text { Applications } \\
\text { (1999 SGA } \\
\text { change) }\end{array}$ \\
\hline $\begin{array}{l}\text { Change in Relative } \\
\text { Real SGA (MA) }\end{array}$ & $0.027^{*}$ & 0.007 & $0.020^{\star * *}$ & 0.044 & -0.021 \\
Change in & $(0.014)$ & $(0.009)$ & $(0.007)$ & $(0.029)$ & $(0.039)$ \\
Unemployment & $0.001^{\star * *}$ & $0.000^{* *}$ & $0.000^{\star * *}$ & 0.001 & -0.000 \\
Rate & $(0.0003)$ & $(0.0002)$ & $(0.0001)$ & $(0.001)$ & $(0.001)$ \\
Constant & 0.176 & $0.234^{* *}$ & -0.058 & $0.689^{\star * *}$ & 0.42 \\
Year Fixed Effects & $(0.157)$ & $(0.099)$ & $(0.071)$ & $(0.060)$ & $(0.29)$ \\
State Fixed Effects & Yes & Yes & Yes & Yes & Yes \\
Observations & Yes & Yes & Yes & Yes & Yes \\
\hline
\end{tabular}

note: ${ }^{* \star} p<0.01,{ }^{* \star} p<0.05,{ }^{*} p<0.1$; Cluster standard errors by state presented in parenthesis 


\begin{tabular}{|c|c|c|}
\hline & Coefficient & $\begin{array}{l}\text { New applications } \\
\text { relative to bottom } \\
\text { earnings group }\end{array}$ \\
\hline \multirow[t]{2}{*}{1990 Dummy } & 807.403 & \\
\hline & $(2252.386)$ & \\
\hline \multirow[t]{2}{*}{$1990 *$ (Earnings in $\$ 300-\$ 500)$} & $-2,419.90$ & $-1,612.50$ \\
\hline & (3055.432) & $(2252.386)$ \\
\hline \multirow[t]{2}{*}{$1990 *$ (Earnings in $\$ 500-\$ 700)$} & $-2,495.40$ & $-1,688.00$ \\
\hline & $(3055.432)$ & $(2252.386)$ \\
\hline \multirow[t]{2}{*}{ 1990* (Earnings > \$700) } & $2,517.10$ & $3,324.50$ \\
\hline & (3055.432) & $(2252.386)$ \\
\hline \multirow[t]{2}{*}{1999 Dummy } & -512.821 & \\
\hline & $(2163.996)$ & \\
\hline \multirow[t]{2}{*}{$1999 *$ (Earnings in $\$ 300-\$ 500)$} & 814.1 & 301.279 \\
\hline & (3055.432) & (2163.996) \\
\hline \multirow[t]{2}{*}{$1999^{*}$ (Earnings in $\$ 500-\$ 700$ ) } & 789.6 & 276.779 \\
\hline & (3055.432) & (2163.996) \\
\hline \multirow[t]{2}{*}{ 1999*(Earnings > \$700) } & 196.1 & -316.721 \\
\hline & $(3055.432)$ & $(2163.996)$ \\
\hline \multirow[t]{2}{*}{ Earnings in $\$ 300-\$ 500$} & 61.9 & \\
\hline & (921.247) & \\
\hline \multirow[t]{2}{*}{ Earnings in $\$ 500-\$ 700$} & 68.4 & \\
\hline & (921.247) & \\
\hline \multirow[t]{2}{*}{ Earnings $>\$ 700$} & $1,416.90$ & \\
\hline & (921.247) & \\
\hline \multirow[t]{2}{*}{ Change in Unemployment Rate } & $1,607.520 * * *$ & \\
\hline & $(584.145)$ & \\
\hline \multirow[t]{2}{*}{ Constant } & 231.829 & \\
\hline & $(660.808)$ & \\
\hline Observations & 48 & \\
\hline R-squared & 0.38 & \\
\hline \multicolumn{3}{|l|}{ Standard errors in parentheses } \\
\hline \multicolumn{3}{|l|}{$* * * p<0.01, * * p<0.05, * p<0.1$} \\
\hline \multicolumn{3}{|c|}{$\begin{array}{l}\text { Note: Omitted category is earnings }<\$ 300 \text {. Shading identifies group earning } \\
\text { between old and new SGA levels in } 1990 \text { and } 1999 \text {, respectively. }\end{array}$} \\
\hline
\end{tabular}


Figure 1. Real Substantial Gainful Activity (SGA) Amount by Year (2009 dollars)



Source: SSA and Consumer Price Index published by BLS 
Figure 2A. Density of Relative Changes in SGA by State in 1999 (\% of state average annual wage)



Figure 2B. Density of Relative Changes in SGA by State in 1999 (geographic distribution)

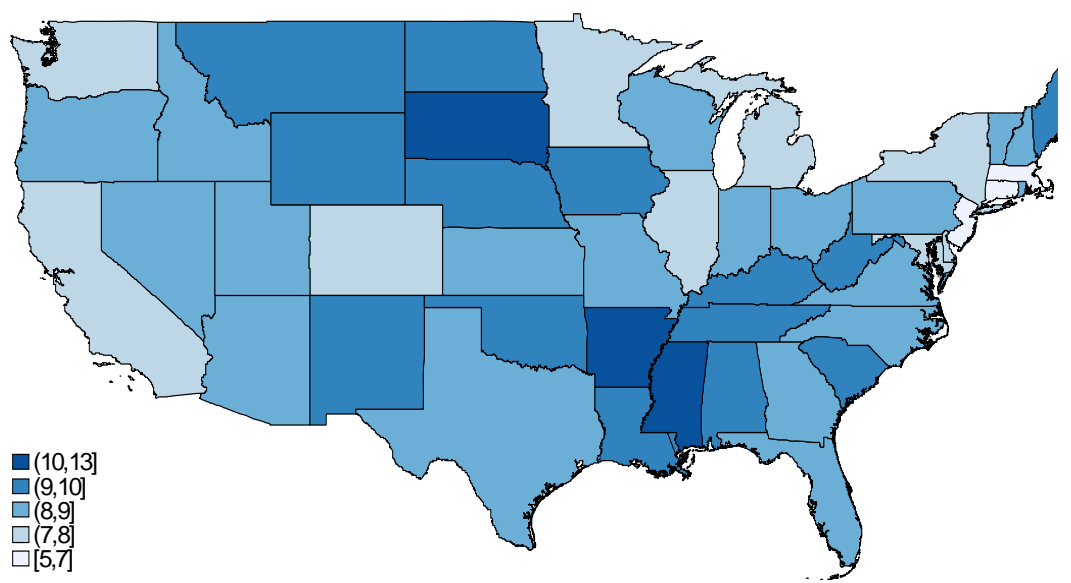


Figure 3. SSDI Budget Constraint Before and After SGA Change and under Benefit Offset

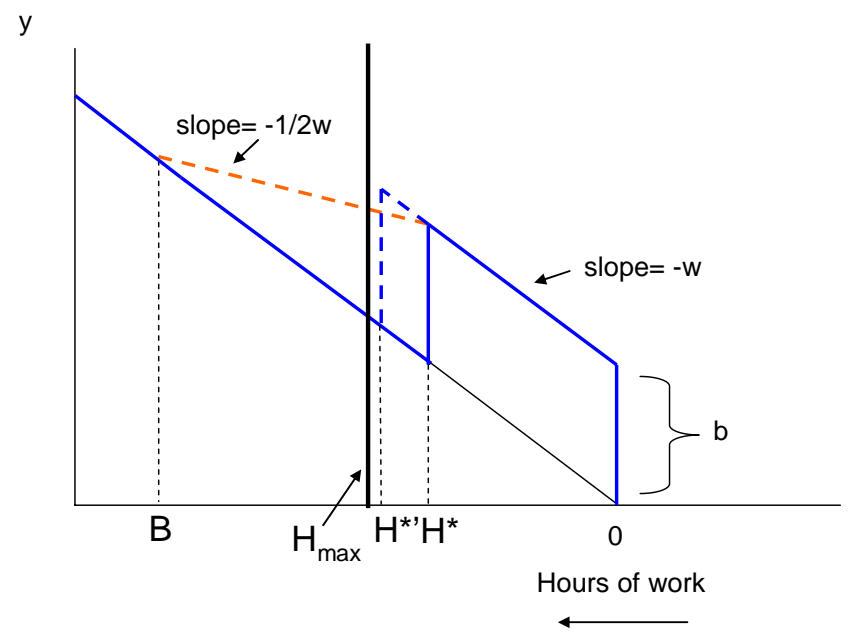


Figure 4. Monthly SSDI Applications and the National Unemployment Rate

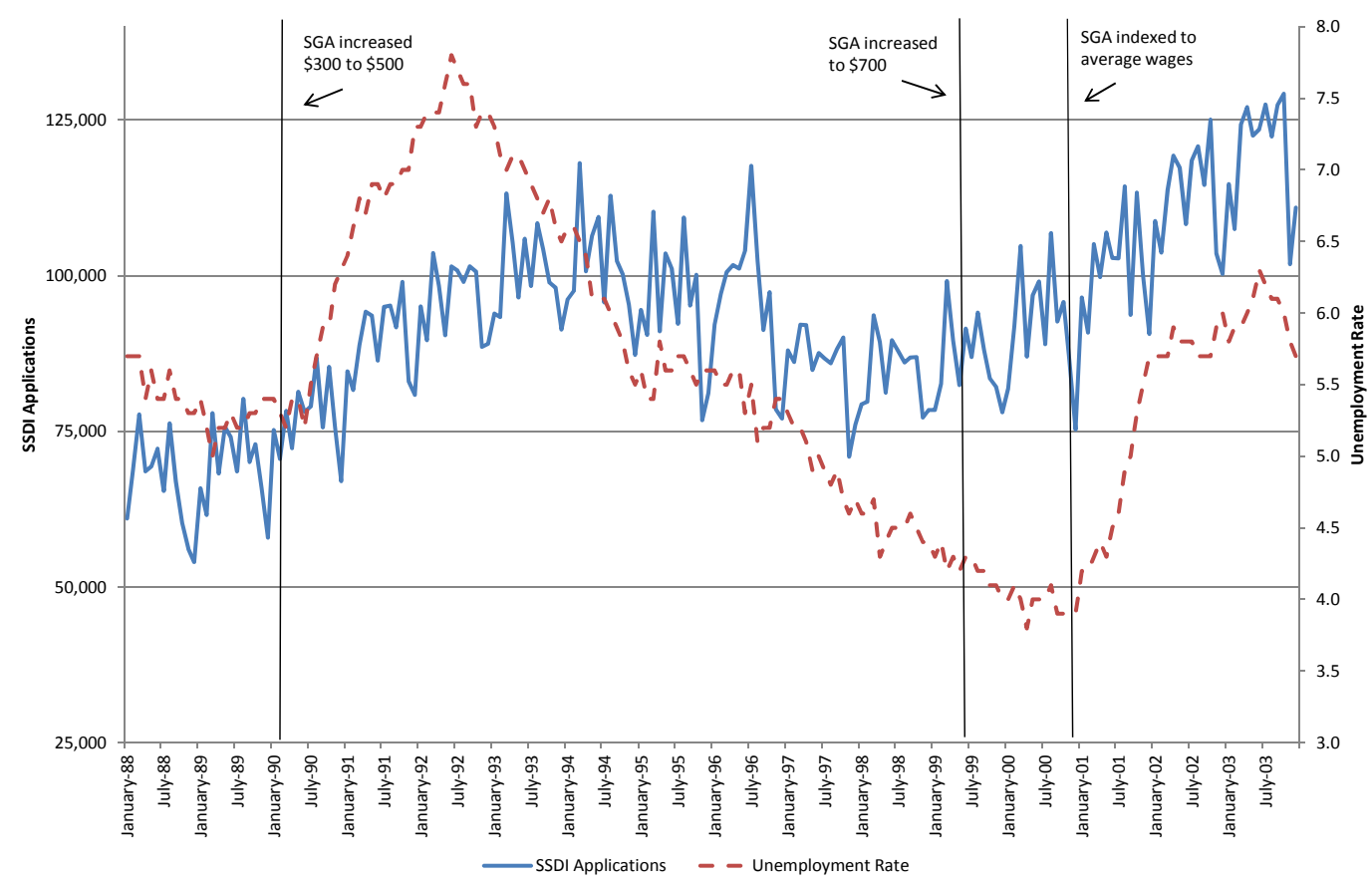


Figure 5A. Applications in 1998 by State and Relative SGA

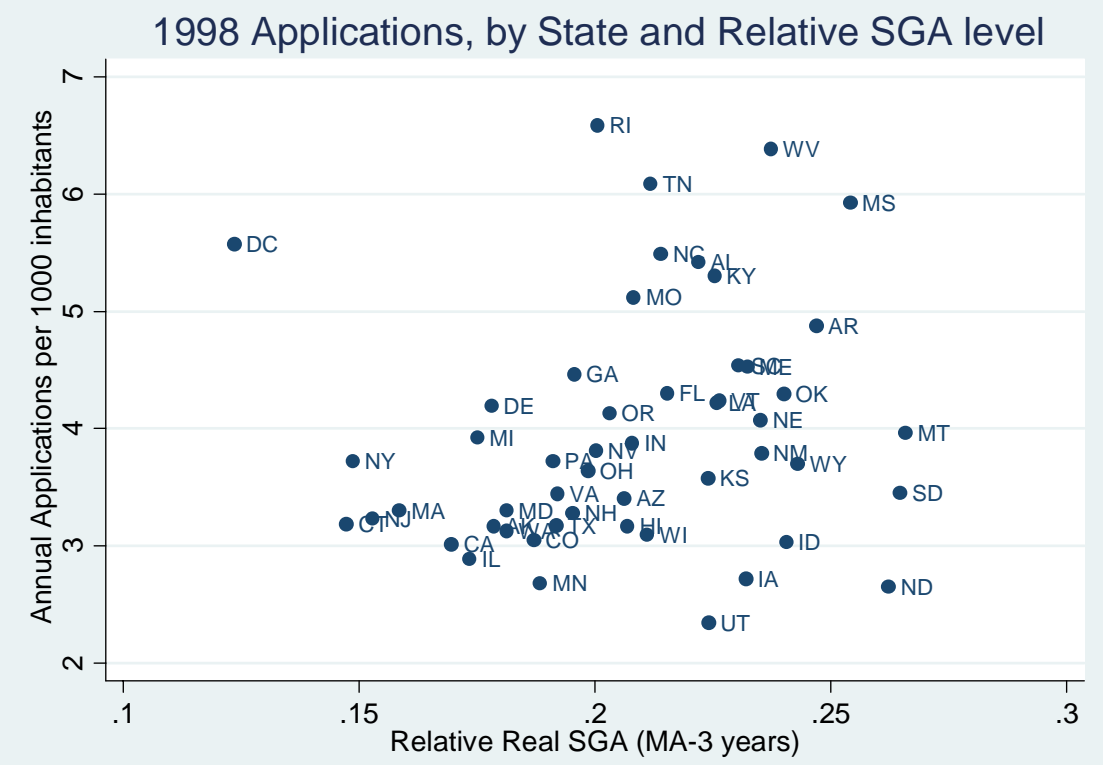

Figure 5B. Applications in 2000 by State and Relative SGA

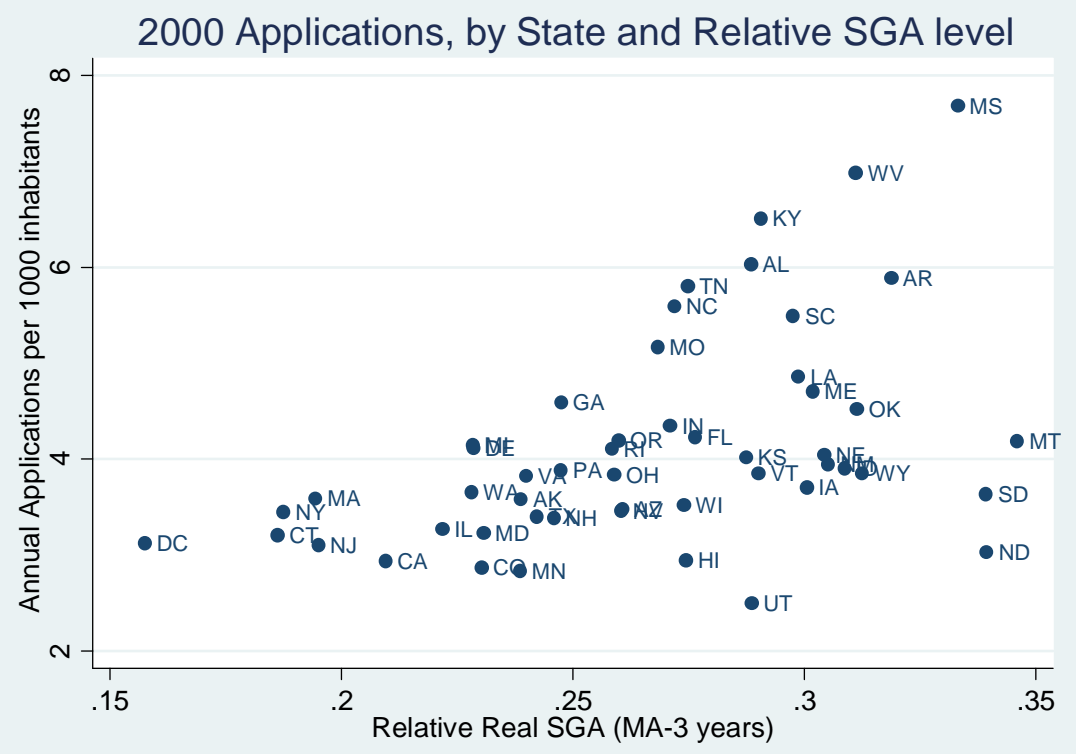


Figure 6A. Changes in State Applications between 1998 and 1996 and Change in State Relative SGA

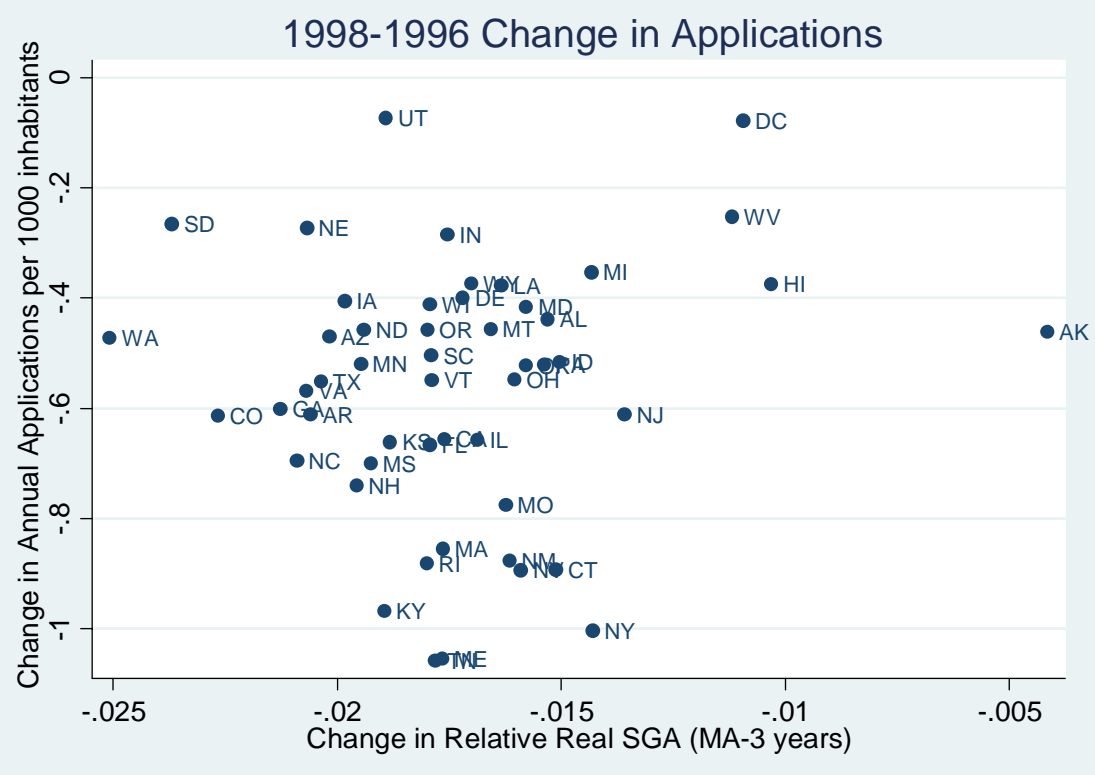

Figure 6B. Changes in State Applications between 2000 and 1998 and Change in State Relative SGA

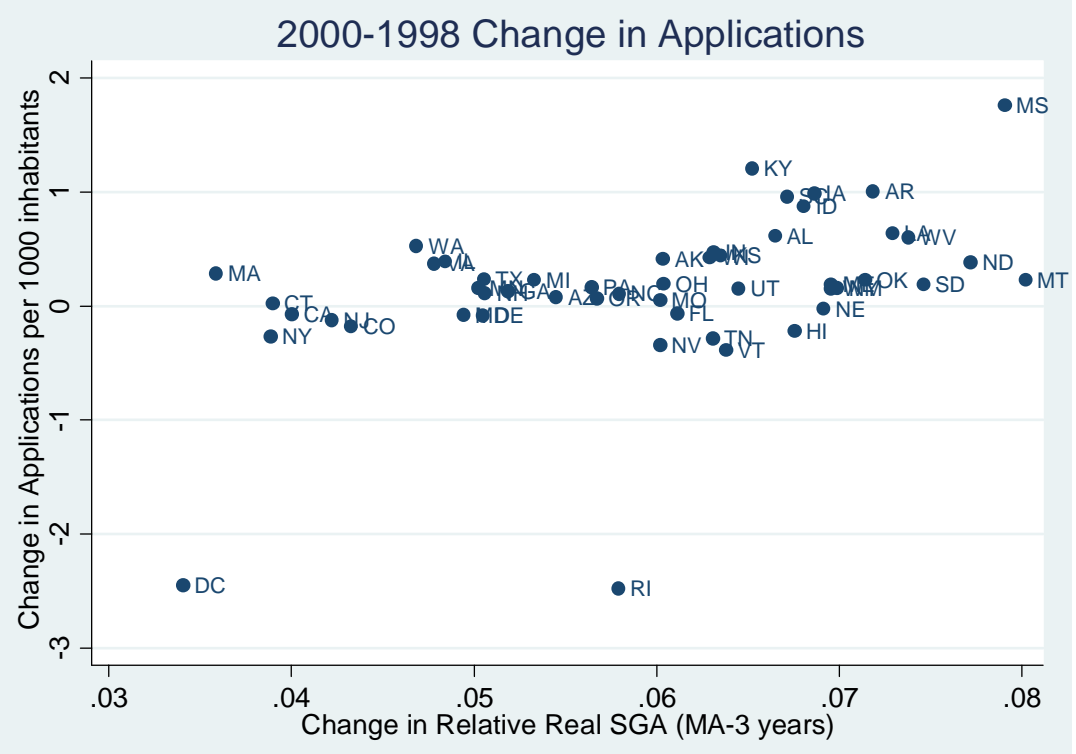


Figure 7. December Applications by Monthly Earnings in Prior Year

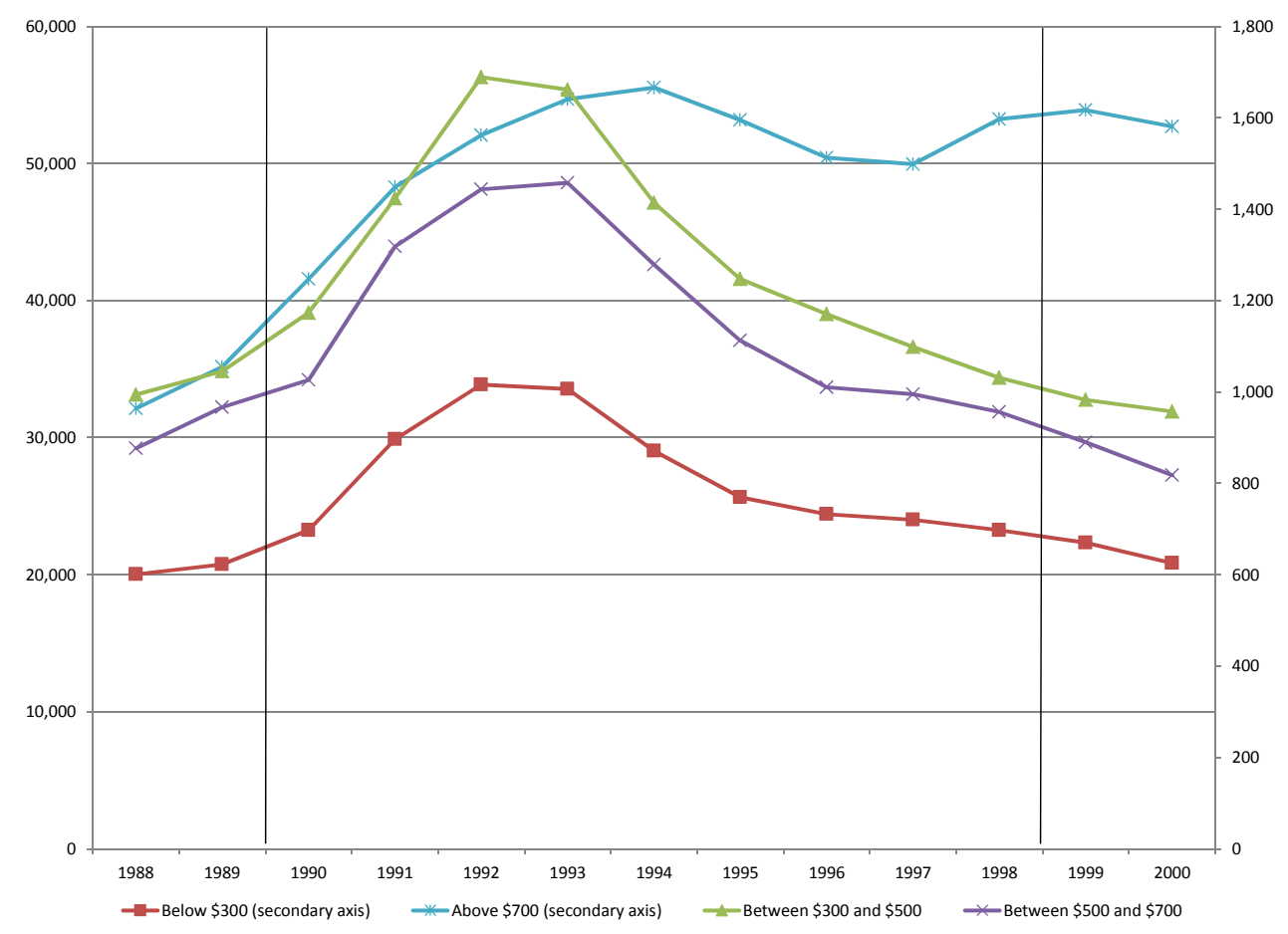

